\title{
Regional Variation in Initiation of Childbearing in Kenya
}

\author{
By \\ Lawrence D.E. Ikamari \\ Population Studies and Research Institute, \\ University of Nairobi, Kenya
}

\begin{abstract}
This paper seeks to establish the effect of region of residence on the initiation of child bearing in Kenya and to determine whether its effect has changed overtime. The data used is drawn from the 1998 and 2003 Kenya Demographic and Health Surveys. The Cox proportional hazard models are used to analyse the data. The results revealed that the region of residence has a significant effect on the initiation of child bearing in Kenya and that the effect remains significant even in the presence of the controls for education, age at first marriage, type of place of residence and religion. The effect of the region of residence on in the initiation of childbearing remains more or less the same across the three generations.
\end{abstract}

Key words= region, initiation of childbearing/age at first birth, effect, covariates, Kenya 


\section{Introduction}

The birth of the first child is the first visible outcome of the fertility process. The first birth marks a woman's transition into motherhood. The birth of a child is an event of great social and individual significance and its importance is recognised in all human societies (Morgan and Rindfuss, 1999; Blossfeld and Huinink, 1991). It signifies the transition of a woman into a new social status, i.e. parenthood with its related expectations and responsibilities. It marks the sexual and social maturity of the woman. It plays a significant role in the future life of each individual woman and has a direct relationship with fertility (Davis and Blake, 1965; Bongaarts, 1982).

The age at which childbearing begins usually influences the number of children a woman bears throughout her reproductive period in the absence of any active fertility regulation. Generally, women who start childbearing early have a longer period during which to have children than the women who start childbearing later. They also tend to have low or no education. Delaying the onset of childbearing may allow women to pursue higher education, vocational training and to participate actively in gainful employment that will improve their socioeconomic status and autonomy. In Kenya as well in some parts of sub-Saharan Africa, age at first birth has been increasing gradually over the last two decades (CBS et al., 2004; Ezeh and Dodoo, 2001; Gupta and Mahy, 2003). The rising age at first birth is considered as one of the factors in the recent fertility decline in some parts of sub Saharan Africa (Kirk and Pillet, 1998; Hardwood-Lejeune, 2000)

Although age at first birth is important in an individual's life history and in explaining fertility and mortality transitions, few studies have been undertaken on the initiation of childbearing in Kenya in the recent past. Therefore little is known about the determinants of age at first birth in Kenya. A comparative study by Gupta and Maly (2004), that involved eight sub-Saharan countries, shows that girl's education from about the secondary school level onwards was found to be the only consistently significant variable affecting the risk of having a birth by age of 18 in Kenya.

Studies elsewhere that included all women in the reproductive age (15-49) have, however, identified a number of factors that seem to influence the age at first birth (Gaisie, 1984; Rao and Murty, 1987; Rindfuss and St.John; 1983; Thornton and Teachman, 1995, Jejeebhoy, 1995; Achiempong et al., 2003, Mulder, 2003; Choe et al., 2004, Gyimah, 2003). For example, Choe et al. (2004) found that the women's education, region of residence and ethnicity were the main covariates of the timing of motherhood in Nepal.

This paper seeks to establish the effect of region of residence on the initiation of childbearing since many recent studies indicate substantial regional variation in many demographic phenomena in Kenya (CBS et al. 2004; Ikamari, 1996, 2005; Brockerhoff and 
Hewett, 1998) and its effect on the initiation childbearing in Kenya has largely remained unknown and undocumented.

In Kenya there are significant socio-economic regional variations and the regions have been impacted differentially by modernisation. There are eight provinces in Kenya. Generally due to historical and political reasons, Nairobi, Central and some parts of the Rift Valley province are more economically developed than the other provinces located at the periphery of the Capital City of Nairobi, which is the seat of government. These regional socioeconomic disparities are bound to affect the timing of childbearing. We would expect women residing in the more developed provinces to start having children later than their counterparts in the less developed provinces as the majority would be educated and have more opportunities for career development outside the household (CBS, 2002; CBS et al. 2004; Ikamari, 2005; Brockerhoff and Hewett, 1998, UNDP, 2006).

Furthermore, there are discernible regional cultural variations in Kenya, as one or two ethnic groups predominantly inhabit each of the eight regions. For example, Central Province is predominantly inhabited by the Kikuyu, Coast Province by the Mijekenda, Nyanza by the Luo and Kisii, Western Province by the Luhya, Eastern by Kamba, Embu and Meru, Rift Valley by the Kalenjin, North Eastern by the Somali and Boran, while Nairobi Province is metropolitan (CBS, 2002).
Each ethnic group has its own socio-cultural ideologies about childbearing and its initiation. These ideologies are composed of the norms, beliefs and values as well as the practices that are likely to influence the onset of childbearing and the overall reproductive performance of a given society. It is likely that each cultural group may stress certain aspects in their reproductive institutions. These group norms, ideals and beliefs have been used to explain ethnic variation in the timing of marriage and childbearing (Addai and Trovato, 1999; Arnaldo, 2004). We would also expect significant variation in the initiation of childbearing across the regions of Kenya due to the cultural differences.

We have also included in this paper some of the other factors that have been indicated in the demographic literature to be closely associated with the woman's age at first birth elsewhere. These include education, type of place of residence, religion and age at first marriage. These factors serve mainly as controls.

We hypothesize that region of residence and each of the other factors discussed above has a significant effect on the age at first birth and that their relative effects have changed over time. Due to limitation of the KDHS data used here, it is not possible to examine some of the pathways through which the region of residence affects a woman's age at first birth. However, we shall examine its effect in the presence of the control for one proximate variable, namely, age at first 
marriage. If the effect of the region of residence is substantially reduced in its presence, then it will be established that the region of residence affected age at first birth through age at first marriage. However, if its effect is not reduced or is increased instead then, it will be established that the region of residence affected age at first birth independently of this proximate variable.

Therefore we have included age at first marriage as one of the control variables. This variable is used as proxy for individual attitudes towards family life and procreation. It is not designed to capture the difference of having a first birth between never married and married women. Usually the nature association between the age at first marriage and the initiation of childbearing is rather difficult to pin down in situations where the ordering of these two events is not very clear in a woman's life. In Kenya, as in many societies, the ordering of these two events is not very clear in the sense that whereas the majority of first births occur soon after getting married, some first births occur before marriage. In addition, in some instances an ex-nuptial birth may instigate a marriage. To overcome this problem, all women who had a first birth before marriage were excluded from analysis.

It is worthwhile to mention that educational attainment variable was measured as at the time of the survey. As discussed extensively in the demographic literature, there is a problem in principle with the use of educational attainment as a determinant of the onset of childbearing if education is attained later than the initiation child bearing. However, in the Kenyan context the highest education level is usually attained before the onset of child bearing, at least for most women, because childbearing is generally incompatible with schooling particularly at secondary and lower levels and is socially discouraged. Furthermore school attendance removes the girls from the domestic environment and offers literacy and exposure to new ideas and value systems that may compete with the traditional customs, values and beliefs that promote early marriage and childbearing (Westoff, 1992, Caldwell et al., 1983). For example, Westoff (1992) has demonstrated with the data from the recent DHS from sub Saharan Africa that higher education delays marriage and postpones childbearing among women in the region.

In order to examine whether or not the effects of the selected factors on the age at first birth have changed over time, three birth cohorts of women are used in the analysis. A birth cohort is linked to a particular historical location, which leads its members to experience similar social forces and cultural settings. New members of the society are socialized to adapt to their own social and historical contexts; thus, each cohort's upbringing inevitably reflects values and practices of its time. Therefore, these three cohorts are indicative of the cultural, socio-economic and political factors that have generally shaped the experiences of these women. The three birth cohorts are the 1948-62, the 1963-73 birth cohort and the 1974-88 birth 
cohort. The 1948-62 birth cohort represents the socio-economic conditions during the 12 year period before Independence (1963); the 1963-73 birth cohort represents the socio-economic conditions during the first ten years of Independence and finally the 1974-88 birth cohort to represents the socioeconomic conditions after 10 years of Independence.

\section{Source of data}

The data used in this study is drawn from the 1998 and 2003 Kenya Demographic and Health Survey (KDHS). These two data sets were combined in order to have a large number of women. These KDHS were conducted to collect data on fertility, marriage, sexual activity, fertility preferences, family planning, maternal and child health, information about HIV/AIDS and other sexually transmitted diseases, information on malaria and use of mosquito nets and domestic violence (NCPD et al, 1999, CBS et al, 2004). The surveys were carried out as part of the world- wide DHS program. The surveys covered a national representative sample of women aged 1549 years. This study focuses on 10,279 women who were aged 15-49 years at the time of both of these surveys. As earlier explained these 10,279 women do not include women who had a first birth before marriage.

\section{Method of data analysis}

The dependent variable is the women's age at first birth. Our start time is age 13. This may be interpreted as survival time from non- parenthood state to parenthood state. Throughout this interval, women may either have a birth or be right censored at the time of the survey. Censored cases require special treatment in estimating exposure time, and as such, ordinary regression procedures are not appropriate (Allison, 1995). We, therefore use continuous time event history analysis techniques (Allison, 1984, 1995). In particular, the general proportional hazard (Cox) model is used to assess the effect of region of residence and the other covariate on the timing of first birth. The use of Cox regression in studying demographic processes such as the marriage is fairly common in the literature (Bracher and Santow, 1998; Choe et al., 2004; Gyimah, 2003, Arnaldo, 2004, Ikamari, 2005).

The model is generally described as:

$$
h(t, X)=h_{0}(t) e^{\beta_{i}} x_{i}
$$

Where $h(t, X)$ is the hazard at time $t$ for an individual, say a woman, with a given set of explanatory variables denoted by bold $X$, where $h_{0}(t)$ is a baseline hazard function that is left unspecified, and $e_{i} x_{i}$ is a vector of explanatory variables which is exponentiated ( Kleinbuam and Klein, 2005).

Model fitting is done stepwise. Using the pool sample of 10,279 women, four models will be fitted. Model I will contain only one only region of residence as an explanatory variable. This is done due to the importance of region of residence as portrayed in the literature. Model 2 will contain two variables namely region of residence and education. It therefore 
assesses the relative effect of region of residence in the presence of the control for education. Model 3 has three explanatory variables, namely region of residence, education and age at first marriage. It thus assesses the effect of region of residence in the presence of the controls for education and age at first marriage. Finally, Model 4 is the full model that includes all the covariates. The results of these analyses are presented in Tables 2 . Finally only two models are fitted on each of the three birth cohorts. For each of the birth cohorts, Model 1 will contain only the variable denoting the region of residence and Model 2 will contain all the covariates and therefore will be the full model and the results obtained are presented in Table 3 .

We present the results as risk ratios, which represent the relative likelihood of a woman with the specific characteristic of having a first birth in comparison to a woman who would be in the appropriate reference group. The risk ratio of the reference group or category is one (1.00). If the risk ratio of a given category is greater than 1.00 , this indicates increased likelihood of the risk of having a first birth, and when the risk ratio is less than 1.00 , it indicates a lower risk of having a first birth compared to the reference group. In this analysis, a variable will be reported as having a significant effect, if its effect on the risk of first birth is statistically significant at least at the 5 per cent level of significance.

Table 1 depicts the percentage distribution of the study population of 10,279 women according to the selected covariates and birth cohort. The 1948-62 birth cohort has 2475 members and $97 \%$ of them had had their first birth as at the time of the survey. 3361 women belonged to the 1963-73 birth cohort and $94.9 \%$ of them had had a first birth as at the time of the survey. Finally, the 1974-88 birth cohort has 4443 members and $65 \%$ of them had had their first birth at the time of the survey. 
Table 1: Percentage distribution of covariates: Kenya, 1998-2003

\begin{tabular}{|c|c|c|c|c|}
\hline \multirow[b]{2}{*}{ Covariates } & \multirow{2}{*}{$\begin{array}{l}\text { Pooled } \\
\text { sample }\end{array}$} & \multicolumn{3}{|c|}{ Birth Cohort } \\
\hline & & $1948-62$ & $1963-73$ & $1974-88$ \\
\hline \multicolumn{5}{|l|}{ Region of residence } \\
\hline Nairobi & 10.6 & 6.5 & 10.6 & 12.9 \\
\hline Central & 12.5 & 11.5 & 13.7 & 12.0 \\
\hline Coast & 15.2 & 16.6 & 16.1 & 13.2 \\
\hline Eastern & 12.5 & 13.1 & 12.1 & 12.8 \\
\hline Nyanza & 15.6 & 16.7 & 13.8 & 16.3 \\
\hline Rift Valley & 21.7 & 22.7 & 22.5 & 20.5 \\
\hline Western & 11.9 & 12.5 & 11.2 & 12.0 \\
\hline \multicolumn{5}{|l|}{ Level of education } \\
\hline No education & 14.7 & 32.8 & 11.5 & 31.9 \\
\hline Primary & 55.9 & 45.8 & 53.0 & 63.7 \\
\hline At least secondary & 29.4 & 21.4 & 35.5 & 29.1 \\
\hline \multicolumn{5}{|l|}{ Type of place of residence } \\
\hline Urban & 27.7 & 18.7 & 28.7 & 31.9 \\
\hline Rural & 72.3 & 81.3 & 71.3 & 68.1 \\
\hline \multicolumn{5}{|l|}{ Religion } \\
\hline Catholic & 26.1 & 26.4 & 25.3 & 26.5 \\
\hline Protestant \& other Chrision & 63.7 & 62.9 & 64.2 & 63.8 \\
\hline Other & 10.2 & 10.7 & 10.5 & 9.7 \\
\hline \multicolumn{5}{|l|}{ Age at first marriage } \\
\hline Not married & 21.1 & 4.2 & 10.2 & 38.8 \\
\hline ? 16 years & 26.4 & 37.0 & 27.4 & 19.7 \\
\hline 17-19 years & 29.1 & 32.3 & 30.0 & 26.6 \\
\hline ? 20 years & 23.4 & 26.5 & 32.4 & 14.8 \\
\hline \multicolumn{5}{|l|}{ Birth Cohort } \\
\hline 194862 & 24.1 & ---- & ---- & --- \\
\hline $1963-73$ & 32.7 & ---- & ---- & ---- \\
\hline 197488 & 43.2 & ---- & ----- & ---- \\
\hline Sample size & 10279 & 2475 & 3361 & 4443 \\
\hline
\end{tabular}

Source: Primary Analysis of the 1998 and 2003 KDHS data. 


\section{Results}

\section{Pool Sample}

Table 2 presents the results of fitting the hazard proportional models to the pooled sample of 10279 women. The results in Model 1 indicate that the region of residence has a statistically significant effect on the timing of first birth. The risk of first birth varies significantly across the provinces. The risks of first birth are higher in all the six provinces than in Nairobi. For instance, the risk of first birth is 1.81 times higher in the Rift Valley province as compared to Nairobi province.

In Model 2, the effect of region of residence on the age at first birth has been modestly reduced in the presence of the control for level of education. For example, the risk of having a first birth among women in Coast province is reduced from 1.71 to 1.39 .

In Model 3, the effect of region of residence has further been reduced in the presence of the control of women's education and age at first marriage. In fact, the odds of first birth among women in Coast province are no longer significantly different from those for women in Nairobi province. Also the odds of first births among women in Nyanza province are now only slightly different from those for women in Nairobi province. These results mean that most women in Coast, Nyanza, Eastern Rift Valley and Western province have lower education and that they marriage earlier than women in Nairobi and Central provinces.
The results in Model 3 clearly indicate that age at first marriage is a significant covariate of age at first birth. Early marriage is closely associated with early onset of childbearing. The risk of first birth for women who married before or at the age of 16 is almost 5 times higher than among women who married when they were at least 20 years old. These results imply that most women in Coast, Nyanza, Eastern, Rift Valley and Western Province have lower education attainment and that they marry earlier than women in Nairobi and Central Provinces.

In the full model (Model 4) which has six covariates, only four covariates have statistically significant net effects on the risk of first birth. These covariates are the region of residence, age at first marriage, birth cohort and education. It is clearly evident that the effect of region of residence is still significant though greatly reduced. However, odds of having a first birth among women in Coast province and those in Nyanza province are no longer statistically different from those for women in Nairobi.

The net effect of age of first marriage on the risk of first birth are still stronger than they were in Model 3, indicating that its observed effect on the age at first birth is independent of the region of residence, type of place of residence, religion and the birth cohort of the woman. As expected the results with respect to the birth cohorts indicate that women in the older cohorts were more likely to initiate childbearing earlier than younger women. For instance women in 
the age cohort of 25-34 were 1.72 times as the age cohort 15-24 years. likely to initiate childbearing as women in

Table 2: Hazard Models of the risk of first birth: Kenya, 1998-2003

\begin{tabular}{|c|c|c|c|c|}
\hline & Model 1 & Model 2 & Model 3 & Model 4 \\
\hline \multicolumn{5}{|l|}{ Region } \\
\hline Nairobi (RC) & 1.00 & 1.00 & 1.00 & 1.00 \\
\hline Central & $1.49^{* * *}$ & $1.41^{* * *}$ & $1.40^{* * *}$ & $1.28^{* * *}$ \\
\hline Coast & $1.71^{* * *}$ & $1.39^{* * *}$ & 1.09 & 1.07 \\
\hline Eastern & $1.46^{* * *}$ & $1.26^{* * *}$ & $1.26^{* * *}$ & $1.13^{*}$ \\
\hline Nyanza & $1.71^{* * *}$ & $1.51^{* * *}$ & $1.19^{*}$ & 1.12 \\
\hline Rift Valley & $1.81^{* * *}$ & $1.53^{* * *}$ & $1.37^{* * *}$ & $1.26^{* *}$ \\
\hline Western & $1.65^{* \star *}$ & $1.47^{* * *}$ & $1.31^{* * *}$ & $1.21^{*}$ \\
\hline \multicolumn{5}{|l|}{ Education } \\
\hline None (RC) & & 1.00 & 1.00 & 1.00 \\
\hline Primary & & $0.76^{* * *}$ & 1.09 & $1.21^{*}$ \\
\hline At least Secondary & & $0.50^{* * *}$ & 1.03 & 1.08 \\
\hline \multicolumn{5}{|l|}{ Place of residence } \\
\hline Urban (RC) & & & & 1.00 \\
\hline Rural & & & & 1.07 \\
\hline \multicolumn{5}{|l|}{ Religion } \\
\hline Catholic (RC) & & & & 1.00 \\
\hline Protestant \& other & & & & 0.90 \\
\hline Christian & & & & 1.09 \\
\hline Other & & & & \\
\hline \multicolumn{5}{|l|}{ Age at first marriage } \\
\hline Not married & & & $0.50^{* * *}$ & $0.66^{* * *}$ \\
\hline$=16$ years & & & $4.90^{* * *}$ & $5.32^{* * *}$ \\
\hline 17-19 years & & & $2.04^{* * *}$ & $2.24^{* * *}$ \\
\hline$=20$ years $(\mathrm{RC})$ & & & 1.000 & 1.00 \\
\hline \multicolumn{5}{|l|}{ Birth Cohort } \\
\hline 1974-88 (RC) & & & & \\
\hline 1963-73 & & & & $1.57^{* * *}$ \\
\hline $1948-62$ & & & & $1.67^{* * *}$ \\
\hline
\end{tabular}

Notes: Significance: ${ }^{* * *} \mathrm{p}<0.000,{ }^{* *} \mathrm{p}<0.01,{ }^{*} \mathrm{p}<0.05$.

Source: Primary Analysis of the 1998 and 2003 KDHS data. 


\section{Birth Cohorts}

Table 3 presents the results of the analysis on each of the three cohorts of women. In gross models (Model 1), region of residence has a significant effect on age at first birth among women in all the three birth cohorts. The gross effect of region of residence is significant across the cohorts and but appears to be stronger in the younger cohorts than in the older cohort (1948-62). However, in the full models (Model 2 of each cohort), the effect of region of residence is substantially reduced and among the older cohort (1948-62) the effect of region is no longer statistically significant. The net effect of region of residence is strongest among the 1963-73 birth cohort.

Education does not have a statistically significant net effect among younger birth cohort (1974-88) but has significant net effects among the older cohorts. However, it is the only the odds of first birth among women with primary education that are significantly different from those for women with no education; they are higher than those for women with no education in the two older cohorts (1948-62 and 1963-73).

Similarly, the age at first marriage is closely associated with the onset of childbearing in all the three cohorts. In each cohort, the risks of first birth for women who married before age 20 are substantially and statistically higher than those for women who married when they were at least 20 years old. Furthermore, the risks of first birth for single women in all the cohorts are lower compared those for women who married when they were at least 20 years old. The effect of age at first marriage is stronger among the older, particularly among the 1963-73 birth cohort than in the younger cohort.

Type of place has a net statistically significant effect only among younger cohort (1974-88). In among these women, the risk of childbearing is significantly higher among rural women compared to urban women. This means that younger rural women are more likely to initiate childbearing earlier than younger urban women. 
Table 3: Hazard Models of the risk of first birth by age cohort, Kenya: 19982003 KDHS

\begin{tabular}{|c|c|c|c|c|c|c|}
\hline \multirow[b]{2}{*}{ Covariates } & \multicolumn{6}{|c|}{ Birth Cohort } \\
\hline & \multicolumn{2}{|c|}{$1948-62$} & \multicolumn{2}{|c|}{$1963-73$} & \multicolumn{2}{|c|}{$1974-88$} \\
\hline & $\begin{array}{l}\text { Model } \\
1\end{array}$ & $\begin{array}{l}\text { Model } \\
2\end{array}$ & $\begin{array}{l}\text { Model } \\
1\end{array}$ & $\begin{array}{l}\text { Model } \\
2\end{array}$ & $\begin{array}{l}\text { Model } \\
1\end{array}$ & $\begin{array}{l}\text { Model } \\
2\end{array}$ \\
\hline \multicolumn{7}{|l|}{ Region of residence } \\
\hline Nairobi (RC) & 1.00 & 1.00 & 1.00 & 1.00 & 1.00 & 1.00 \\
\hline Central & $1.30 * * *$ & 1.11 & $1.35^{* * *}$ & $1.37^{* * *}$ & $1.59 * * *$ & $1.36^{* *}$ \\
\hline Coast & $1.31^{* * *}$ & 0.92 & $1.60^{* * *}$ & $1.28^{* * *}$ & $1.84^{* * *}$ & 1.03 \\
\hline Eastern & $1.41^{* * *}$ & 1.03 & $1.65^{* * *}$ & $1.35^{* * *}$ & $1.30^{* * *}$ & 1.08 \\
\hline Nyanza & $1.75^{* * *}$ & 1.04 & $2.50 * * *$ & $1.57^{* * *}$ & $1.39^{* * *}$ & 0.96 \\
\hline Rift Valley & $1.50^{* * *}$ & 1.02 & $2.05^{* * *}$ & $1.62^{* * *}$ & $1.75^{* * *}$ & $1.23^{* *}$ \\
\hline Western & $1.55^{* * *}$ & 1.10 & $1.78^{* * *}$ & $1.50 * * *$ & $1.61^{* * *}$ & $1.16^{*}$ \\
\hline \multicolumn{7}{|l|}{ Level of education } \\
\hline No education (RC) & & 1.00 & & 1.00 & & 1.00 \\
\hline Primary & & $1.27^{* *}$ & & $1.29^{* *}$ & & 1.08 \\
\hline At least secondary & & 1.02 & & 1.06 & & 0.99 \\
\hline $\begin{array}{l}\text { Type of place of resic } \\
\text { Urban (RC) }\end{array}$ & \multicolumn{6}{|c|}{ Type of place of residence } \\
\hline Rural & & 1.00 & & 1.00 & & 1.00 \\
\hline & & 1.05 & & 1.08 & & $1.11^{*}$ \\
\hline \multicolumn{7}{|l|}{ Religion } \\
\hline Catholic (RC) & & & & & & \\
\hline Protestants & & 1.00 & & 1.00 & & 1.00 \\
\hline Other & & 0.93 & & 1.00 & & 1.02 \\
\hline & & 0.89 & & 0.86 & & 1.01 \\
\hline \multicolumn{7}{|l|}{ Age at first marriage } \\
\hline Not married & & $1.27^{* * *}$ & & 0.92 & & $0.54^{* * *}$ \\
\hline$=16$ years & & $5.29 * * *$ & & $7.70^{* * *}$ & & $4.21^{* * *}$ \\
\hline 17-19 years & & $2.52^{* * *}$ & & $3.09 * * *$ & & $1.72^{* * *}$ \\
\hline$=20$ years $(\mathrm{RC})$ & & 1.00 & & 1.00 & & 1.00 \\
\hline
\end{tabular}

Notes: Significance: ${ }^{* * *} \mathrm{p}<0.000,{ }^{* *} \mathrm{p}<0.01,{ }^{*} \mathrm{p}<0.05$.

Source: Primary Analysis of the 1998 and 2003 KDHS data.

\section{Discussion}

This paper investigated the effect of region of residence and a few other selected covariates on the age at first birth and sought to assess whether their effects differ across generations of women. The results obtained using the pooled data drawn from the 1998 and 2003 Kenya Demographic and Health Surveys revealed that the regional of residence has a significant effect on the initiation of 
childbearing. Substantial regional variations in the initiation of childbearing in Kenya are apparent. As expected women in less economically developed regions such as Nyanza, Coast and Western province and some parts of the Rift Valley were significantly more likely initiate childbearing early compared to women in the more developed regions such as Nairobi and Central province.

The effect of the region of residence was statistically significant in each of the birth cohorts. Its effect varied in each of the three birth cohorts of women. However its effect on both the pooled sample of all women and in each of the three cohorts of women was significantly diminished in the presence of the controls for the age at first marriage and education. This implies that its effect was largely due the differences in the age at first marriage and women's educational attainment across the provinces. This means that the women in the more developed regions were educated and married later than their counterparts in the less developed regions of Kenya.

Age at first marriage was a significant covariate of age at first birth. Early marriage is closely associated with early onset of childbearing. The risk of first birth for women who married before or at the age of 16 was much higher than women who married when they were at least 20 years old. Similarly the risk of first birth for women who married when they were between ages 17 and 19 was much higher while the risk of first birth for single women is much lower compared to women who married when they were at least 20 years or more. These results indicate that single women are significantly less likely to initiate childbearing compared to married women. In most communities in Kenya ex-nuptial childbearing is culturally and socially discouraged and most Kenyan unmarried women would want to avoid initiating child bearing before marriage. Furthermore, having an ex-nuptial birth usually puts the concerned women to very many disadvantageous situations. For example a recent study has shows that women who have ex-nuptial births have a lower chance of getting married (Ikamari, 2005).

In the multivariate models, education was weakly associated with the initiation on of childbearing. The effect of education is more or less the same in all the two older cohorts of women but was insignificant in the 1974-88 birth cohort. In the older cohorts the risk of first birth for women with primary education was significantly higher than that of women with no education and those with at least secondary education. The effect of education was substantially reduced when the age at first marriage are introduced in the model, implying that education influences the age at first birth through the age at first marriage. These results suggest that the highly educated women are likely to delay marriage and also delay the onset of child bearing. These results are consistent with the results found elsewhere (Choe et al., 2004; Gupta and May, 2004; Achiempong et al., 2003; Mulder, 2003). 
Lawrence D.E. Ikamari: Regional Variation in the Initiation of Childbearing in Kenya

In the pool sample and in the two older birth cohorts (1948-62 and 1963-73), the results pertaining to net effect of education are particularly interesting. Women with primary education are indicated as having a statistically significant higher risk of getting a first birth compared to women with no education. Similarly, the risk of having first birth among women with higher education is not statistically different from that for women with no education. This indicates imply that small amounts of education may be unexpectedly linked to earlier initiation of child bearing, as exposure to limited schooling may undermine traditional practices of sexual abstinence and while at the same has not adequately facilitated the acquisition of life skills and related reproductive behaviour such as increased use of contraception and negotiation of sex often associated with increased schooling (Bledsoe et al. 1999).

The results clearly indicated that women in the older cohorts were more likely to initiate childbearing earlier than younger women. For instance women in the age cohort of 25-34 were 1.72 times as likely to initiate childbearing as women in the age cohort 15-24 years. This indicates that there has been a rise in the age at first birth among women in Kenya. These results are consistent with those reported in the 1998 and 2003 KDHS Country Reports(NCPD et al., 1999; CBS et al, 2004)

Finally, both the type of place of residence and religion has insignificant net effects on the risk of first birth in the pooled sample of women as well as in each of the three birth cohorts. Hence they are not important in determining age at first birth in Kenya.

This study has implications for programs that seek to rise the age at first birth. Since significant regional variations exist initiation of childbearing in the country, interventions that seek to rise the age at first birth, ought to take into account these wide regional variations. The results obtained revealed that much of the observed regional variation in the initiation of childbearing was due the regional differences in the age at first marriage and women's educational attainment. It is, therefore, crucial to target young women with accurate information on reproductive health to provide them with basic life skills and reproductive health in order to enable them to avoid early sexual activity and ultimately early childbearing. In addition, user- friendly reproductive health services should be availed to the young women who are sexually active to enable them avoid unwanted and mistimed births.

These efforts should target young women, girls in school and those out of school. This should be done throughout the country with more emphasis placed on the less developed regions such as Coast, Nyanza and Western province. Similarly, concerted efforts should be made to expand access to education so that the majority of girls in the whole country attain at least secondary level of education as this one of the important ways of delaying the onset of childbearing which is critical in reducing fertility. 
Due lack of suitable data this study did not investigate some of the pathways through which region of residence influenced the timing of first birth. Similarly, interactions between and among the covariates included in this study have not been investigated. Future studies on this subject should endeavour to seek for the pathways through which the region of residence influences the timing of childbearing in Kenya. In addition, an investigation should be done on the interactions between and among covariates. Furthermore, efforts should be made to establish why women with no education are less likely to start childbearing than those with primary education.

\section{References}

Achiempong, Y.A , Kaluele-Sabiti, I. and Ditlopo, P. 2003. "Analysing cross-sectional data with timedependent covariates: The case of South Africa". Journal of Biosocial Science, 35: 353-365. D0I $10.1017 /$ S0021932003003535.

Addai, I. and Trovato, L. 1999. "Structural assimilation and ethnic fertility in Ghana". Journal of Comparative Family Studies 30(3):409-427.

Allison, P. D. 1995. Survival Analysis Using the SAS System: A Practical Guide, Cary,North Carolina: SAS Institute Inc.
Allison, P.D. 1984. Event History Analysis: Regression for Longitudinal Data. Sage.

Arnaldo, C. 2004. "Ethnicity and Marriage Patterns in Mozambique". African Population Studies vol. 19(1): 143-164.

Bledsoe, C.H., J. B. Casterline, J.A. Johnson-Kuhn, and J.G. Haaga (eds.). 1999. Critical Perspectives on Schooling and Fertility in the Developing World. Washington, DC: National Academy Press.

Blossfeld, H.P., and Huinink, J. 1991."Human capital investments or norms of role transition? How women's schooling and career affect the process of family formation". American Journal of Sociology, 97, 143-168.

Bongaarts, J. 1982. “The FertilityInhibiting Effect of the Intermediate Fertility Variables". In Studies in Family Planning, 13(6/7):179-188.

Brockerhoff Martin and Hewett, P. 1998. Ethincity and Child Mortality in Sub Saharan Africa. Population Council Working Paper No. 107.

Caldwell, J.C., P.H. Reddy, and P. Caldwell. 1983. "The causes of marriage change in South India", In Population Studies 37(3): 343361

Central Bureau of Statistics (CBS) [Kenya], 
2002. Kenya 1999 Population and Housing Census. Analytical Report on Population Dynamics Volume: CBS : Nairobi.

Central Bureau of Statistics (CBS) [Kenya], 2007. Kenya Integrated Household Budget Survey (KIHBS) 2005/06, CBS: Nairobi

Central Bureau of Statistics (CBS) [Kenya], Ministry of Health, and ORC Macro. 2004. Kenya Demographic and Health Survey, 2003.Calverton, Maryland: CBS, $\mathrm{MOH}$, and ORC Macro.

Choe, M. K., Thapa, S and Mistra, V. 2004. "Early marriage and early motherhood in Nepal". Journal of Biosocial Sciences (First published on line 2004) 00: 1-20.

Davis, K. and Blake, J. 1965. “Social Structure and fertility: an analytic framework". In Economic Development and Cultural Change (Chicago, Illinois), Vol.4. No. 3 (April), pp: 221-235.

Ezeh, A. C. and. Dodoo, F. N.A. 2001. "Institutional Change and African Fertility Transition: the case of Kenya". In Genus Vol. LVII no.3-4 Pp.53-73.

Gaisie, S.K. 1984. The Proximate Determinants of Fertility in Ghana. WFS Scientific Reports (53).

Gupta, N. and Mahy, M. 2003.
"Adolescent childbearing in subSaharan Africa: can increased schooling alone raise ages at first birth", Demographic Research, 8(4): 93-106.

Gyimah, S.O. 2003. Women's Educational Attainment and the Timing of Parenthood in Ghana: A Cohort Perspective. Discussion Paper No: 03-04. Department of Sociology, University of Western Ontario, Canada.

Hardwood-Lejeune, A. 2000." Rising age at marriage and fertility in Southern and Eastern Africa". European Journal of Population 17:261-280.

Ikamari, L. 2005. "The effect of education on the timing of marriage in Kenya". Demographic Research 12 (1):1-27.

Ikamari, L. D.E., 1996. Factors affecting child survival in Kenya. PhD Thesis. The Demography Program. The Research School of Social Sciences. The Australian National University. Canberra: Australia.

Jejeebhoy, S.J. 1995. Women's Education, Autonomy, and Reproductive Behavior: Experience from Developing Countries. Oxford: Clarendon Press.

Kirk, D. and Pillet, B. 1998. “Fertility levels, trends and differentials in sub-Saharan Africa in 1980s and 1990s". Studies in Family Planning, 
29(1):1-22.

Kleinbaum, D. G. and Klein, M. 2005. Survival Analysis: A Self Learning Text. Second Edition. Springer Science. New York.

Morgan, S. P. and Rindfuss, R. R.1999. "Re-examining the link of early childbearing to marriage and to subsequent fertility", In Demography 36(1):59-75.

Mulder, C. H. 2003. “The Effects of Singlehood and Cohabitation on the Transition to Parenthood in the Netherlands". In Journal of Family Issues, 24(3):291-313.

National Council for Population and Development (NCPD), [Kenya], Central Bureau of Statistics, and Macro International Inc. (MI). 1999. Kenya Demographic and Health Survey 1998. Calverton: Maryland: NCPD, CBS, MI.
Rao, K. V. and Murty, K. S., 1987. "Covariates of age at first birth in Guyana: A hazard model analysis", In Journal of Biosocial Science 19: 427-438.

Thornton, A. A. G., and Teachman, J. D. 1995. "The influence of school enrolment and accumulation on cohabitation and marriage in early adulthood". In American Sociological Review, 60, 762-774.

United Nations Development Programme. 2006: Kenya National Human Development Report 2006. Human Security and Human Development: A deliberate Choice. UNDP: Nairobi

Westoff, Charles F., 1992. Age at Marriage, Age at first Birth and Fertility in Africa. World Bank Technical Paper \# 169. Washington D.C.: The World Bank. 